\title{
Arquitetura óptica: análise de um modelo de associação de espelhos cilíndricos como representação dos prédios da Procuradoria Geral da República ${ }^{+* 1}$
}

\section{Jair Lúcio Prados Ribeiro ${ }^{2}$}

Doutorando do Programa de Pós-Graduação em Educação em Ciências Universidade de Brasília

Brasília - DF

\section{Resumo}

Os dois prédios da Procuradoria Geral da República em Brasília possuem formato cilíndrico e são cobertos por vidros refletores, assemelhando-se a uma associação de dois espelhos convexos cilíndricos. A partir de um modelo experimental usando duas lixeiras cilíndricas cromadas, é discutida a formação da imagem de um prédio por reflexão no outro e as aberrações ópticas presentes. O artigo busca mostrar um possível diálogo entre as disciplinas da arquitetura e da física, o qual é raro na literatura acadêmica.

Palavras-chave: Reflexão; Óptica geométrica; Arquitetura.

\begin{abstract}
The two buildings of Attorney General's Office in Brasilia are shaped like cylinders and covered in reflective glass, resembling an association of two cylindrical convex mirrors. Through an experimental model with two cylindrical chrome bins, we discuss how the image of a building is generated by reflection on the other, and also the present optical
\end{abstract}

\footnotetext{
${ }^{+}$Optical architecture: analysis of a cylindrical mirrors association model as a representation of Attorney General's Office buildings

* Recebido: dezembro de 2014.

Aceito: maio de 2015.

${ }^{1}$ Esse artigo expõe alguns resultados preliminares da nossa pesquisa (em andamento) no Programa de Doutorado em Educação em Ciências (PPGEduc), na Universidade de Brasília, sobre as possibilidades de uso do espaço urbano para o ensino de temas da óptica.

2 E-mail: jairlucio@gmail.com
} 
aberrations. The article shows a possible dialogue between the disciplines of Architecture and Physics, which is rare in the academic literature.

Keywords: Reflection; Geometrical Optics; Architecture.

\section{Introdução}

Brasília, capital do Brasil, foi inaugurada em 1960. Seu desenho urbanístico foi concebido por Lúcio Costa, mas a maior parte dos prédios e monumentos públicos que a tornam um patrimônio arquitetônico foi projetada por Oscar Niemeyer, o qual criou diversas soluções arquitetônicas arrojadas para suas obras na cidade. Tais formas diferenciadas, segundo o próprio, se deveram ao caráter monumental da cidade:

Para os que visitavam Brasília, gostassem ou não dos meus projetos, tranquilizavame a certeza de que não poderiam dizer terem visto antes coisa parecida. Deles queria ouvir o que ouvi de Le Corbusier subindo a rampa do Congresso: "Aqui há invenção” (NIEMEYER, 1978, p. 44).

O conjunto de prédios que compõe a Procuradoria Geral da República (PGR) em Brasília foi inaugurado em 2002 e se inclui nessa tradição da busca pelo inusitado. Desde a concepção inicial por Niemeyer, foram previstos dois prédios principais em formato cilíndrico, circundados por prédios adicionais de menor altura. Os dois edifícios principais foram projetados como cilindros de dimensões idênticas, mas com diferentes estruturas de sustentação (Fig. $1)$.

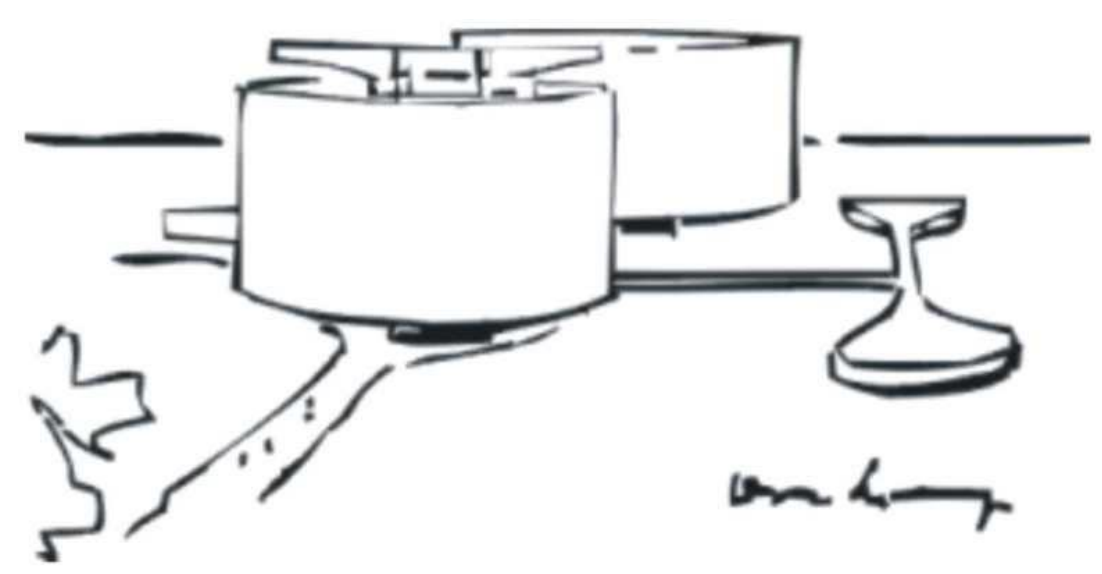

Fig. 1 - Desenho de Oscar Niemeyer para o conjunto de prédios da Procuradoria Geral da República. Fonte: <http://www.pgr.mpf.mp.br/conheca-o-mpf/visitacao-apgr/copy_of_sobre-o-predio/maquete.jpg >. Acesso: 02 dez. 2014. 
Devido à proximidade entre os dois prédios (interligados por duas passarelas) e o uso de películas refletoras em seus vidros, o conjunto se assemelha a uma associação de dois espelhos convexos cilíndricos. É possível observar com facilidade a imagem de um prédio gerada por reflexão nos vidros do outro (Fig. 2), e até mesmo imagens formadas por reflexões adicionais (as quais aparecem escurecidas na fotografia).

$\mathrm{Na}$ Fig. 2, os prédios aparecem azulados, mas a película refletora que recobre seus vidros não possui essa tonalidade, como outras fotografias do conjunto arquitetônico, disponíveis na internet, demonstram. A foto foi obtida em uma manhã típica da época de seca brasiliense, com céu claro e ausência de nuvens. Assim, as superfícies refletiram para o observador a luz azul predominante (espalhada pela atmosfera), resultando na coloração observada.

A discussão das relações entre a arquitetura e a física é rara na literatura acadêmica. Os poucos livros e artigos acadêmicos dedicados a esse entrelaçamento se preocupam em ser um acompanhamento didático para alunos de arquitetura cursando disciplinas universitárias de física (ACIOLI, 1994; SALU, 2009) ou relatos descritivos de tais cursos (SALAMO et al., 1979; ANASTASSAKIS, 1982). Tais cursos tendem a contemplar temas da mecânica, transmissão de calor e acústica, merecendo a óptica pouco destaque, exceto no tocante a projetos de iluminação de ambientes interiores.

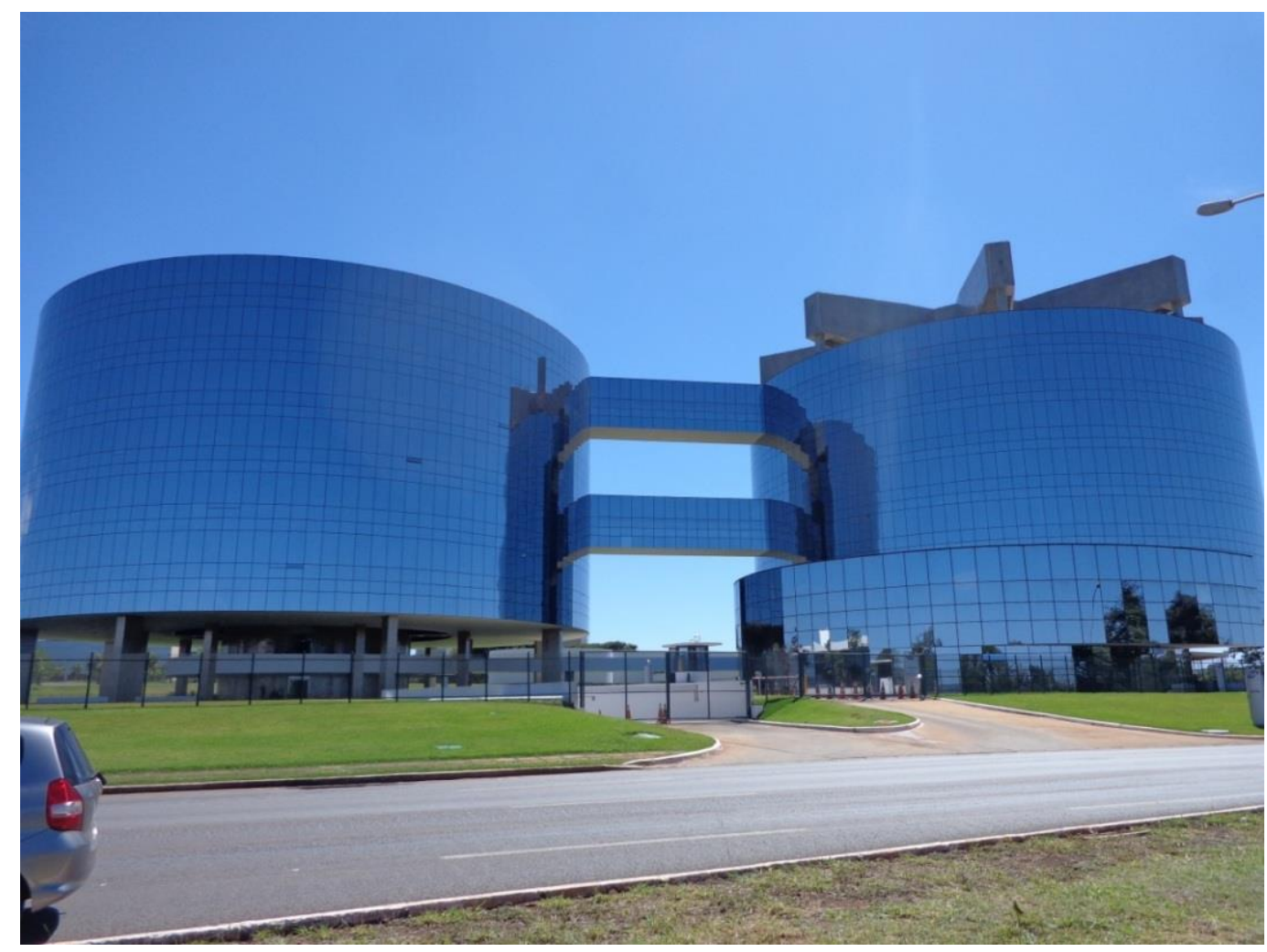

Fig. 2 - Os dois prédios principais da Procuradoria Geral da República, em Brasília. As imagens virtuais refletidas dos edifícios são vistas próximas às pontes de interligação. 
Uma notável exceção é o trabalho de Vollmer e Möllmann (2012), inspirador da linha de pesquisa desenvolvida no presente artigo. Os autores estudaram casos reais de prédios com formato côncavo e recobertos com vidros refletores, os quais produzem zonas aquecidas em seus arredores, devido à concentração dos raios solares após a reflexão nas superfícies côncavas $^{3}$. O artigo propõe a construção de modelos em escala reduzida, usando espelhos comuns, para o estudo de tais zonas de concentração de radiação. Na pesquisa aqui exposta, os dois prédios da PGR foram representados por duas lixeiras cilíndricas cromadas.

Propõe-se nesse trabalho uma sequência de atividades experimentais que podem ser conduzidas com estudantes de ensino médio e sugestões para a sua discussão, a fim de que as imagens observadas nos edifícios sejam interpretadas e a reflexão em superfícies curvas possa ser tratada de forma diversa da tradicional, tal como exposto nos livros didáticos.

Embora as edificações da PGR possam servir de apoio e exemplo à discussão, as atividades podem ser conduzidas sem a necessidade da interconexão com a linguagem arquitetônica. Entretanto, consideramos que abrir mão de tal discussão é desperdiçar uma oportunidade didática relevante, no tocante à contextualização de um conteúdo e estabelecimento de um diálogo ainda raro entre duas disciplinas.

\section{Espelhos cilíndricos: revisão bibliográfica}

Nos livros-texto de física voltados para o ensino médio, espelhos curvos com geometria diferente da esférica são discutidos de forma esparsa. É ponto comum às obras referenciadas a seguir o tratamento aproximado para a formação de imagens em espelhos esféricos, baseado nas condições de aproximação de Gauss, em especial a necessidade de raios paraxiais (próximos ao eixo principal) e o grau de curvatura do espelho ser pequeno.

Percebeu-se na revisão que os espelhos cilíndricos nem mesmo são citados em alguns livros didáticos, como nos textos de Bonjorno et al. (2010), Guimarães et al. (2013) e Guimarães e Fonte Boa (2005). Outras obras (ANJOS, 2005; RAMALHO et al., 2007) fazem referência apenas a espelhos esféricos, mas ao apresentarem fotografias das trajetórias de reflexão de raios paralelos paraxiais, os espelhos mostrados são cilíndricos.

É usual também que as obras de ensino médio (MÁXIMO; ALVARENGA, 2005; RAMALHO et al., 2007; VILLAS-BÔAS et al., 2011; PIETROCOLA et al., 2011; SILVA; BARRETO, 2008) comentem sobre a utilização de espelhos côncavos parabólicos em telescópios, holofotes ou faróis de automóvel, justificando tal uso pela maior nitidez produzida por tal geometria. Os trabalhos de Ramalho et al. (2007) e Silva e Barreto (2008) citam ainda que as imagens sem nitidez ou deformadas podem ser produzidas em espelhos esféricos, mas não estendem essa discussão para outros formatos.

\footnotetext{
${ }^{3}$ Exemplos desse aquecimento produzido por estruturas arquitetônicas foram percebidos em diversas localidades, tais como Las Vegas (VÖLLMER et al. 2012) e Londres (GUERRA, 2013).
} 
Uma apresentação mais detalhista sobre a distorção imagética produzida por espelhos esféricos é encontrada em Villas-Bôas et al. (2011), o qual argumenta sobre a opção por trabalhar apenas com espelhos gaussianos, pois estes não apresentariam as distorções citadas, denominadas aberrações de esfericidade. Como contraponto a tal discussão, um texto complementar é apresentado, com a representação de espelhos esféricos não-gaussianos e uma rápida passagem sobre a cáustica de reflexão, sem que uma imagem do fenômeno esteja presente.

Apenas na obra de Pietrocola et al. (2011) é encontrada uma menção direta aos espelhos cilíndricos e suas aplicações, em particular a técnica artística da representação anamórfica. Tal técnica consiste em representar em uma superfície plana uma imagem que só pode ser vista com nitidez ao ser observada por reflexão em um espelho cilíndrico convexo. Os autores propõem a construção de um desenho anamórfico e a observação de sua reflexão no espelho cilíndrico como uma atividade experimental. Atividades semelhantes à proposta estão disponíveis também na internet (ver, por exemplo, SAMPAIO, 2013).

Foram revisados também livros-texto voltados para o ensino superior, e percebeu-se que mesmo tais obras não dedicam grande atenção a formas geométricas diversas da esfera. Serwey e Jewett (2003) repetem os livros de ensino médio e citam os espelhos parabólicos como ideais para a diminuição das aberrações esféricas, enquanto Knight (2009) e Halliday et al. (2011) nem mesmo relacionam espelhos de formato diferente do esférico em seus textos. Young e Freedman (2009) reforçam a necessidade de se considerar raios paraxiais (aproximadamente paralelos e próximos ao eixo principal) para que as equações de espelhos esféricos possam ser demonstradas e as aberrações esféricas desconsideradas, assim como Nussenzveig (1998). Tipler e Mosca (2008) conduzem argumentação semelhante, e mesmo sem uma citação nominal aos espelhos cilíndricos, apresentam uma fotografia representando a distorção da imagem em um espelho cilíndrico convexo (op. cit., 2008, p.1107). Estes autores relatam de forma breve as características dos diferentes tipos de aberrações ópticas existentes, as quais serão discutidas no item 4 desse artigo.

Mesmo em revistas acadêmicas voltadas para o ensino de física, o tema é pouco frequente, e são os espelhos cilíndricos côncavos que ganham destaque nesses periódicos. Os trabalhos de DeWeerd e Hill (2005) e Catelli e Vicenzi (2004), por exemplo, lidam com as imagens ou curvas cáusticas formadas pela reflexão da luz na superfície interna (côncava) de uma xícara cilíndrica ou no menisco convexo (esférico) do líquido em seu interior. Holzberlein (1982) também lida com um espelho cilíndrico côncavo, detalhando de forma qualitativa como a imagem de um ponto objeto é formada nesses espelhos. DeWeerd e Hill (2005a) retomam essa discussão e apresentam um método algébrico e geométrico para a construção de tal imagem em um espelho cilíndrico côncavo. Como alertado pelos próprios autores, esse método pode ser transposto para o convexo, e sua vertente geométrica será apresentada no item a seguir. 


\section{Imagem de um ponto objeto em um espelho cilíndrico convexo}

A partir da revisão bibliográfica, percebe-se que as aproximações assumidas para a formação de imagens em espelhos esféricos têm sua origem na necessidade de se minimizar as aberrações. Uma aberração óptica ocorre quando a luz emitida por um ponto objeto não gera um único ponto imagem, ou seja, não converge ou diverge de um ponto singular.

Há dois tipos de aberração em óptica: cromáticas e monocromáticas (HETCH, 2002). As aberrações cromáticas são comuns em sistemas refratores, tais como lentes objetivas em máquinas fotográficas e lunetas, e ocorrem devido à variação do índice de refração do material do elemento óptico com o comprimento de onda da luz incidente. Como tal condição é inexistente em sistemas refletores, os mesmos só apresentam aberrações monocromáticas, ou seja, independentes da frequência da luz incidente. Esse subconjunto é denominado aberrações de Seidel, em reconhecimento ao trabalho pioneiro desse pesquisador sobre tais fenômenos nos anos 1850 (op. cit., 2002).

Uma aberração monocromática é nomeada por seu efeito. A curva cáustica, por exemplo, tratada por Catelli e Vicenzi (2004) e Völlmer et al. (2012), é um exemplo de aberração esférica, a forma mais comum. Nessa aberração, o ponto objeto está sobre o eixo principal do espelho, ou os raios são paralelos a este. Já o fenômeno da coma pode ser observado ao se inclinar um espelho côncavo durante a projeção de uma imagem real. Com o espelho paralelo ao anteparo de projeção, esse fenômeno não ocorre, mas se esse paralelismo não é observado, a imagem possuirá pontos com uma "cauda" (a palavra coma tem origem em cometa), caracterizando a coma. Outra possível aberração é verificada quando a ampliação depende da distância de cada ponto de objeto a partir do eixo (TIPLER; MOSCA, 2008), levando à distorção da imagem (em formato de barril ou almofada de alfinetes).

Em um espelho cilíndrico, todas as aberrações citadas estão presentes, mas segundo Hunt et al. (2000), aquela mais diretamente responsável pela imagem observada é o astigmatismo. Nessa situação, para um ponto objeto, são formadas imagens não pontuais, em planos diferentes e perpendiculares entre si. $\mathrm{O}$ astigmatismo é percebido quando essas imagens observadas por diferentes ângulos de visão, sendo apresentada uma alteração nas dimensões e proporções relativas do objeto.

A Fig. 3, construída a partir da sugestão de De Weerd e Hill (2005b), ilustra como tais imagens são conjugadas. Considere um espelho cilíndrico com eixo vertical, tais como os edifícios da PGR estão dispostos. Em um corte vertical, esse espelho é plano (Fig. 3), e forma uma imagem pontual simétrica em relação ao objeto. Entretanto, em um corte horizontal, esse espelho é convexo (Fig. 3), o que resulta em uma imagem mais próxima à superfície. A formação dessa imagem se dá pelo prolongamento imaginário, até o ponto de convergência, dessas reflexões, sendo tais imagens classificadas como virtuais. Como múltiplos cortes horizontais podem ser imaginados, com um ponto imagem resultante em cada um deles, a imagem final produzida por tais reflexões é uma linha vertical. Em um espelho esférico, haveria duas dessas linhasimagem, perpendiculares entre si, para um objeto localizado fora do eixo principal. 
Ao se observar as imagens, o ângulo de visão irá influenciar na percepção dessas imagens (DEWEERD; HILL, 2005b). Assim, dispondo a cabeça na vertical, o observador observará a linha vertical, e com a cabeça inclinada (“deitada de lado"), a imagem parecerá se "reclinar" no plano horizontal, caracterizando o astigmatismo.

O quinto tipo de aberração monocromática é a curvatura de campo, que é verificada quando a imagem de um objeto plano não pode ser focalizada em uma superfície também plana. Os exemplos citados dessa deformação na literatura consultada (JOHNSON, 1960; O'SHEA; HARRIGAN, 1995; HETCH, 2002) envolvem lentes de máquinas fotográficas, as quais geram imagens esféricas de superfícies planas (para efeito de correção, a maioria das lentes objetivas tem distância focal variável com o ângulo de incidência) ou se preocupam com o detalhamento da aberração esférica (RÖMER, 2005; DRUDE, 1959). Entretanto, a despeito da existência de citação na literatura, consideramos que a curvatura de campo é uma aberração importante na análise da imagem em um espelho cilíndrico convexo, pois é fácil perceber que uma figura plana (papel quadriculado) colocada à frente desse espelho revelará uma imagem curva, como mostrado na Fig. 4.

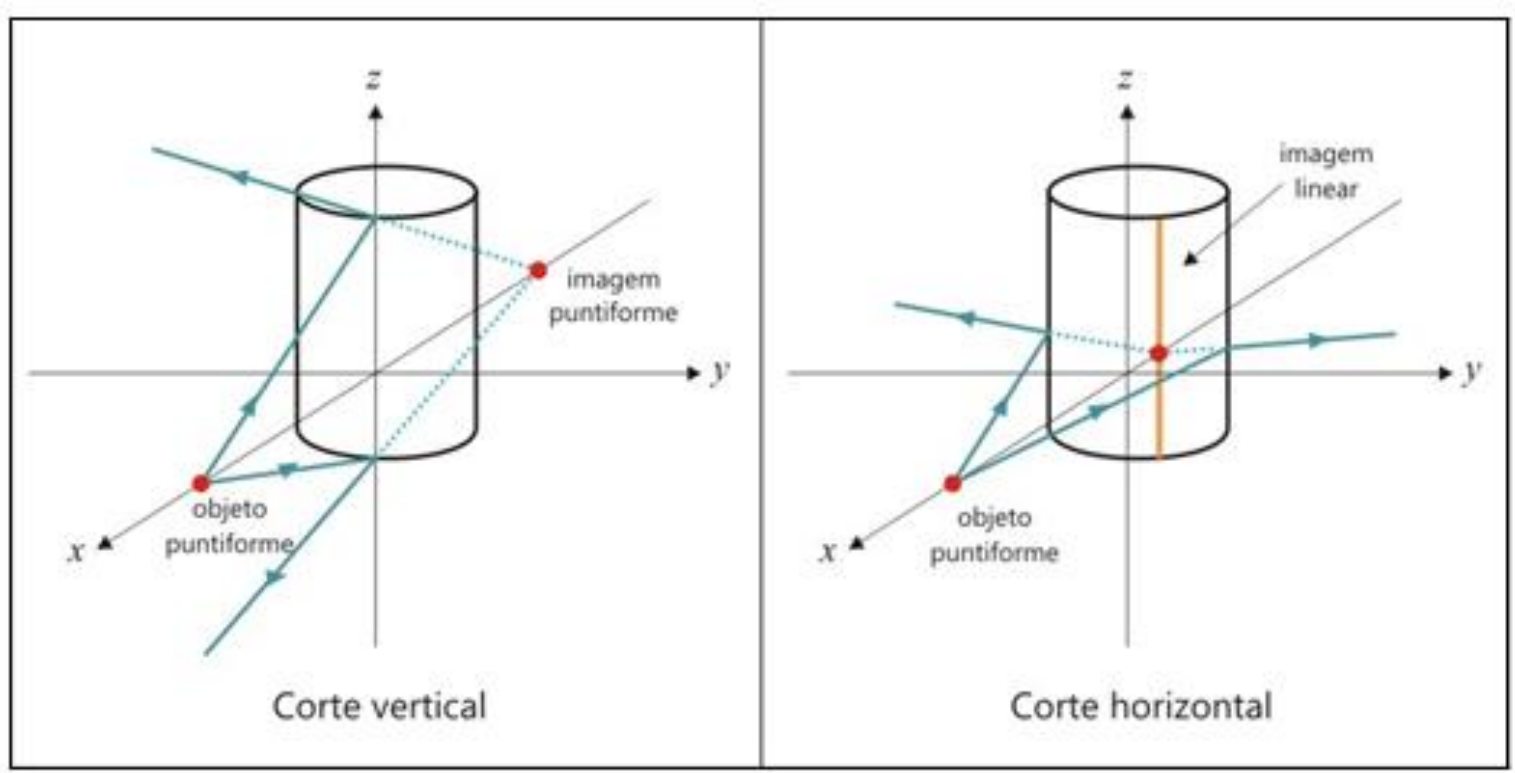

Fig. 3 - Imagens geradas por reflexão em dois planos perpendiculares.

Convém frisar que as cinco aberrações monocromáticas citadas supõem um sistema óptico ideal. No caso aqui descrito, seria necessário considerar dois espelhos cilíndricos com superfícies bem polidas, sem irregularidades. Ao se realizar a atividade experimental, entretanto, percebeu-se que havia pequenas depressões ou protuberâncias na superfície das lixeiras, as quais causaram perturbações adicionais às imagens. 


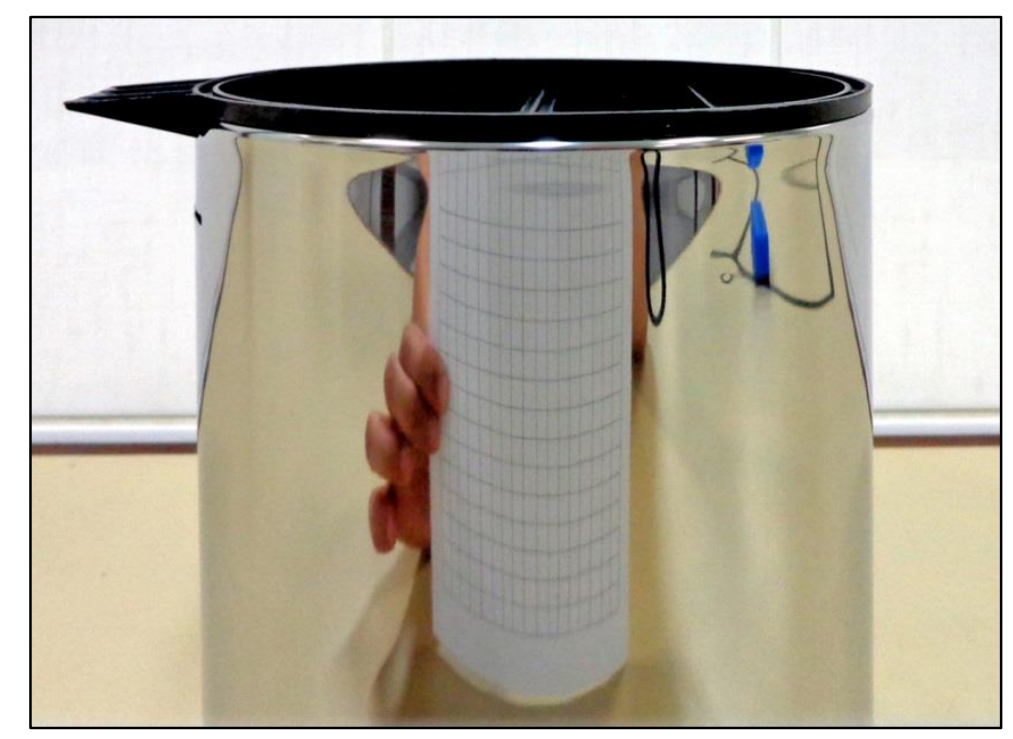

Fig. 4 - Imagem deformada em um espelho cilíndrico convexo devido à curvatura de campo.

\section{As curvas de Niemeyer e os edifícios da PGR}

O problema da forma em arquitetura é tão vasto que pode ser resumido por aforismos contraditórios: segundo Stroeter (1986), para alguns estudiosos do tema, "a forma segue a função", enquanto para outros, "a função segue a forma". É frequente que as obras de Niemeyer funcionem como catalisadores dessa discussão, pela modificação intencional e por vezes surpreendente do ambiente que tais obras produzem, ainda que a ocupação humana seja sua finalidade primária (SILVA, 1994).

A busca por formas inusitadas e belas foi uma constante na arquitetura de Oscar Niemeyer, reconhecido como um dos ícones da arquitetura modernista do século XX (KAMITA, 2012; DURAND; SALVATORI, 2011). Segundo o próprio artista, "quando uma forma cria beleza, ela tem uma função e das mais importantes em arquitetura” (NIEMEYER, 1978, p. 24).

A opção por formas geométricas esteve sempre presente em sua vasta obra, variando desde a simplicidade de um círculo até curvas de contornos aparentemente aleatórios, mas ao contrário intencionais. Era a busca pela surpresa do observador que justificava essa opção: "não raro, era a forma abstrata que me atraía, pura e delgada, solta no espaço à procura do espetáculo arquitetural" (op. cit, 1978, p. 24). Para outro autor, "o uso ousado e habilidoso de curvas é uma característica básica da obra de Oscar Niemeyer, contribuindo significativamente para a sua reputação como criador de formas" (PIZZATO, 2007, p. 43).

As obras de Niemeyer permeiam a paisagem brasiliense desde a construção da nova capital. Apesar da sede da PGR estar prevista no plano urbanístico original de Brasília, os cinco prédios que a compõem fazem parte da fase mais recente de Niemeyer na cidade, entre a década 
de 1990 até a morte do arquiteto em $2012^{4}$. Os seis edifícios da PGR foram construídos entre 1995 e 2002, e compreendem um total aproximado de 70 mil metros quadrados de área construída [SEGRE, p. 277].

Diversas polêmicas envolveram o conjunto arquitetônico, em especial a interferência visual produzida à Praça dos Três Poderes, lugar dos prédios mais tradicionais de Brasília, como o Congresso Nacional e o Palácio do Planalto. Para um crítico (ROSSETI, 2012), a própria configuração cilíndrica dos edifícios da PGR é controversa, pois causa uma expressão construtiva exagerada, devido ao uso impactante dos vidros reflexivos e ao exagero estrutural. Para esse mesmo autor, o uso de vidros refletores como fechamento da fachada se revelou uma solução atípica de Niemeyer, assim como as duas pontes de vidros espelhados que interligam os prédios principais.

Edifícios cilíndricos são recentes como soluções arquitetônicas, e surgiram com o advento do modernismo no século XX. Um detalhamento sobre a arquitetura modernista foge ao escopo desse trabalho, mas cabe ressaltar sua importância: segundo Lara (2005), "o modernismo foi sem dúvida o fenômeno arquitetônico mais importante que o Brasil já teve até hoje".

As primeiras torres cilíndricas envidraçadas de apartamentos (fig.5) foram inauguradas apenas em 1963, em Chicago (SEGRE, 2007). Niemeyer já havia adotado o formato cilíndrico em obras anteriores à PGR, como o Hotel Nacional (1968-1973), o qual é composto de uma única torre cilíndrica espelhada (Fig. 6), evocando castelos medievais (op. cit., 2007, p. 277). Outros projetos de Niemeyer com o formato cilíndrico em destaque são o Parlamento da América Latina (cilindro de vidro escuro em São Paulo, inaugurado em 1989) e a sede do jornal L’Humanité, na região metropolitana de Paris (cilindro de vidro refletor, 1987-1989).

\section{Aparato experimental e sugestões de atividades}

A partir da sugestão de Völlmer (2012), decidiu-se pelo trabalho com um modelo em escala reduzida dos edifícios da PGR, para maior facilidade de análise das imagens obtidas. Outra óbvia razão para essa escolha diz respeito à busca de possibilidade de recriação da pesquisa por outrem: uma obra arquitetônica é por definição imóvel (com raras exceções), sendo necessário o trabalho com um modelo para que a pesquisa possa ser conduzida em localidades diferentes daquela onde se encontra o imóvel.

\footnotetext{
${ }^{4}$ Mesmo após o falecimento de Niemeyer, alguns projetos de sua autoria para Brasília ainda possuem sua edificação prevista para os próximos anos. Uma cronologia da obra de Niemeyer está disponível no sítio oficial <www.niemeyer.org.br>.
} 


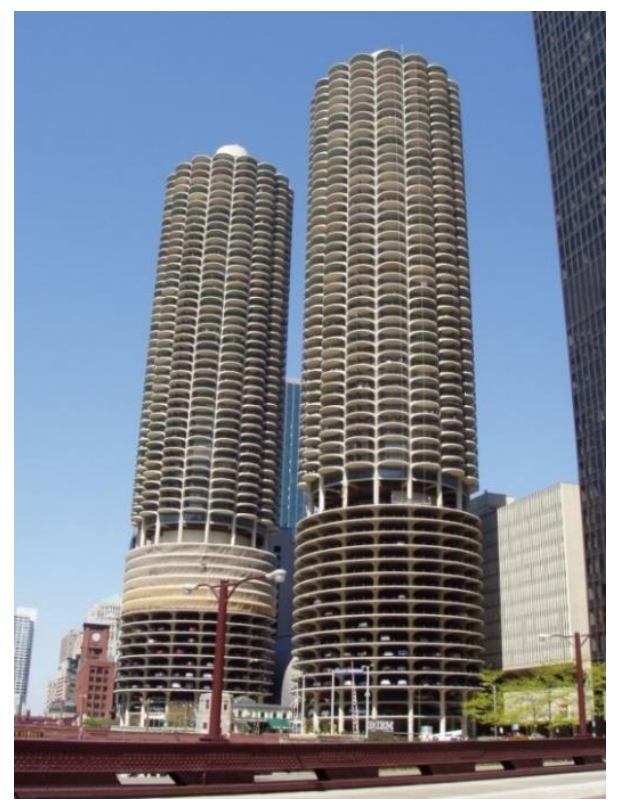

Fig. 5 - Conjunto Marina City em Chicago, projeto de Bertrand Goldberd, inaugurado em 1963. Fonte: 〈http://commons.wikimedia.org/wiki/File:Marina_City_-_Chicago,_Illinois.JPG>. Acesso: 28 nov. 2014.

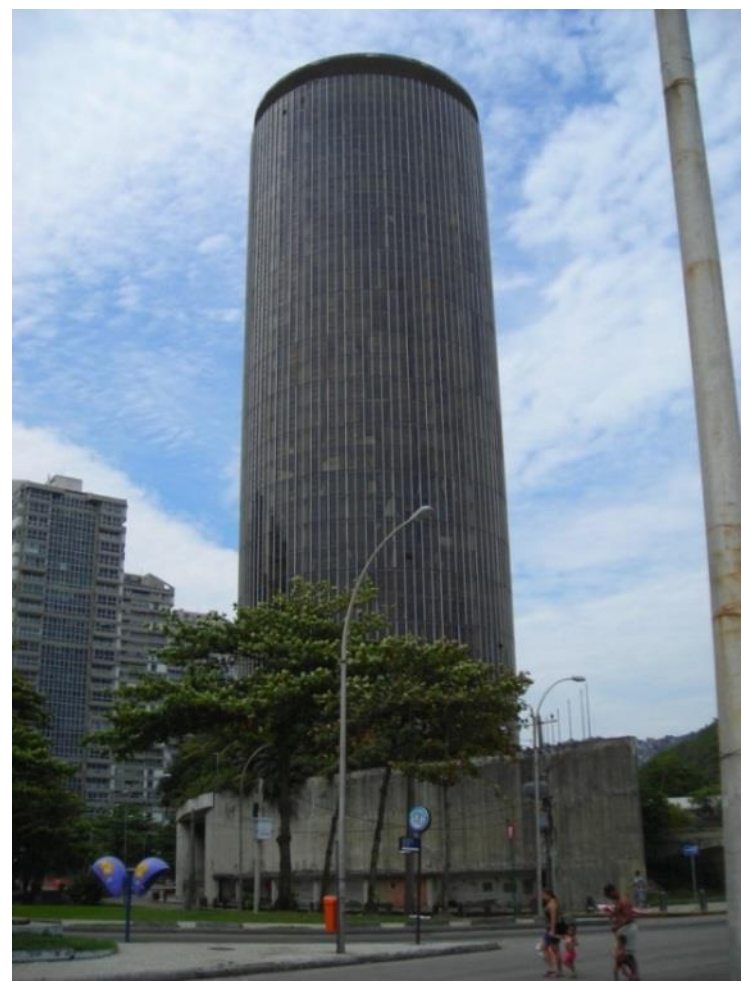

Fig. 6 - Hotel Nacional no Rio de Janeiro, projeto de Oscar Niemeyer, inaugurado em 1973. Fonte: <https://c1.staticflickr.com/1/112/311839512_135c12e00e_b.jpg>. Acesso: 28 nov. $2014^{5}$.

5 As Fig. 5 e 6 utilizadas nesse trabalho possuem licença livre para reutilização não comercial. 
Com vistas à viabilidade econômica do modelo, buscou-se no mercado um objeto cilíndrico espelhado de tamanho razoável e baixo custo. Tubos hidráulicos cromados foram a primeira escolha, mas seu tamanho reduzido inviabiliza uma demonstração mais clara, em especial no tocante à obtenção de fotografias para esse artigo. Contudo, se um professor optar por desenvolver as atividades experimentais aqui sugeridas durante a exposição da óptica geométrica no ensino médio, tais tubos podem ser uma boa opção, a fim de que os próprios estudantes possam manipular o modelo, construir hipóteses e elaborar conclusões a partir da experiência direta e não apenas da observação de uma atividade experimental demonstrativa.

Foram adquiridas então duas lixeiras de aço cromadas ${ }^{6}$ para a construção do modelo, com diâmetro externo de $18 \mathrm{~cm}$ e altura de $30 \mathrm{~cm}$. Apesar das proporções entre tais dimensões não serem as mesmas dos prédios da PGR, o modelo foi considerado conveniente. Os recipientes foram então desmontados, retirando-se as tampas e demais acessórios, buscando-se uma maior exposição da superfície cilíndrica espelhada. Após a desmontagem, foi percebido que uma lixeira era mais alta que a outra em uma pequena margem $(0,5 \mathrm{~cm})$, mas para os fins do experimento, tal diferença não é relevante.

A seguir, apresentamos sugestões de atividades experimentais que podem ser conduzidas com o modelo, além da citada no item 3 (disposição de uma folha de papel em frente ao espelho para a verificação da curvatura de campo). Como tais experimentos são propostos para ensino médio, optamos por apresentar um tratamento mais qualitativo para a discussão dos fenômenos observados, evitando o tratamento algébrico.

\section{V.1 Atividade experimental 1: Verificação da redução da imagem}

Dispondo um dos cilindros na horizontal, um longo papel centimetrado é colocado próximo ao mesmo, conforme mostra a Fig. 7, e observa-se a imagem por diferentes ângulos de visão. A Fig. 7 representa uma vista superior do experimento.

É perceptível pela análise da Fig. 7 que a imagem apresenta um forte grau de redução na direção horizontal da figura, na qual o espelho se apresenta como convexo, em relação ao objeto. Os estudantes podem ser questionados sobre qual seria o hipotético "plano limite" para o fim da imagem, ou seja, qual seria a modificação na imagem observada se o papel fosse infinitamente longo (a alteração seria mínima, pois tal "plano limite" estaria no plano focal do espelho convexo). Outro questionamento possível envolve a posição do observador (câmera), pois devido ao astigmatismo, a forma da imagem se altera quando observada de diferentes posições.

\footnotetext{
${ }^{6}$ Lixeiras HSP-001A (Sertrading/BR) de aço inox, com 3 litros de capacidade cada.
} 


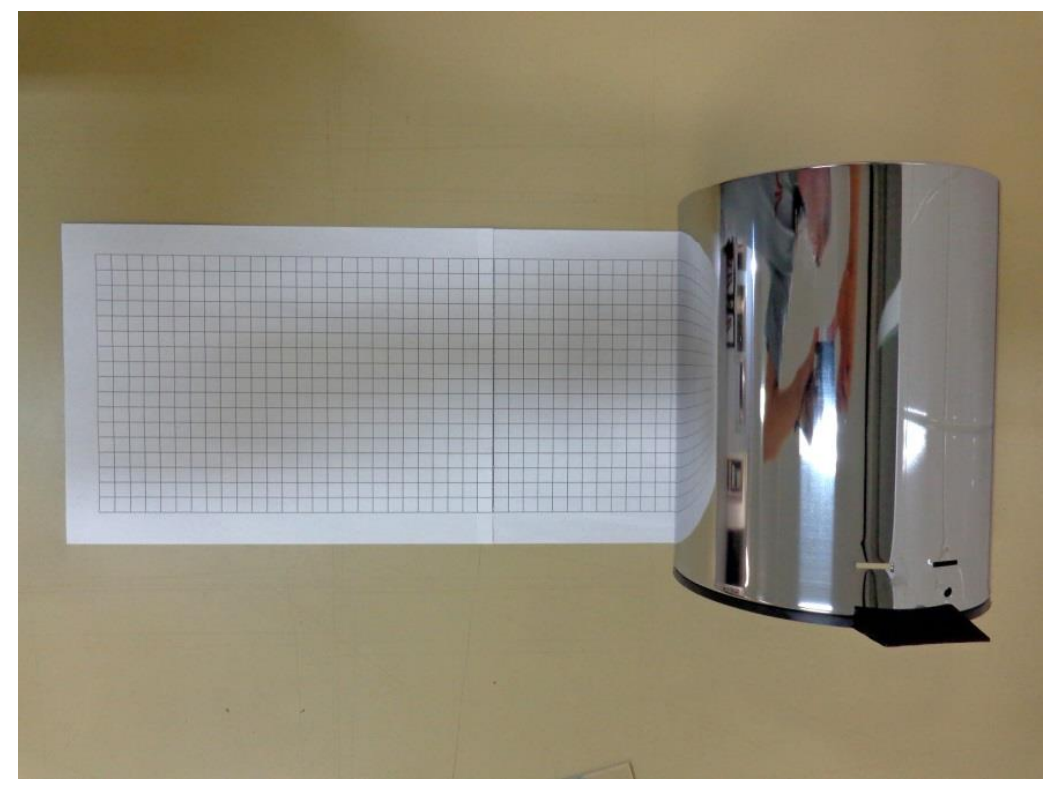

Fig. 7 -Atividade experimental 1.

\section{V.2 Atividade experimental 2: Imagem de um semicírculo em um espelho cilíndrico}

A posição relativa dos prédios da PGR faz com que apenas um semicilindro seja refletido pelo outro. Assim, para melhor compreensão da imagem, um semicírculo de pontos coloridos (Fig. 8), com o mesmo diâmetro da lixeira, foi disposto à frente de um dos espelhos do modelo, e observado de diferentes ângulos, como uma vista superior (fig.8, esquerda) ou lateral (Fig. 8, direita).

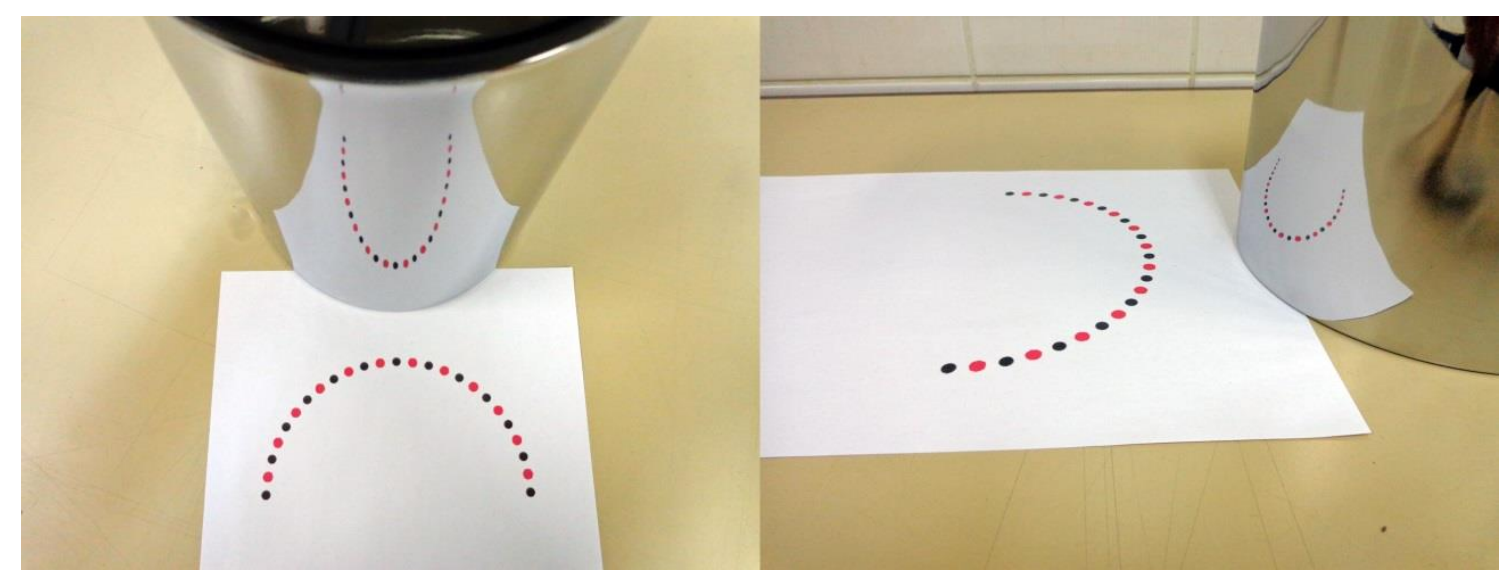

Fig. 8-Atividade experimental 2.

O astigmatismo mais uma vez é percebido na ilustração anterior, pois em uma vista superior, a imagem parece mais alongada e na visão lateral a mesma parece encurtada. A imagem obtida na visão superior parece, em uma primeira observação, ter um formato aproximado de uma parábola, o que não é verdadeiro; ao contrário, é crucial que os estudantes percebam 
que essa forma depende do ângulo de visão, como a segunda fotografia obtida demonstra com facilidade.

A imagem à direita é mais aplicável à interpretação da imagem dos prédios da PGR, pois a fachada dos mesmos é possível de ser observada à distância (Fig. 2). A posição do observador interfere na imagem observada: ao se fotografar lateralmente a imagem, a mesma parece se inclinar para cima (Fig. 8, direita), e essa inclinação aumenta se a câmera for disposta em uma maior altura. Segundo DeWeerd e Hill (2005b), essa modificação é resultante do astigmatismo das imagens dos pontos do semicírculo.

\section{V.3 Atividade experimental 3: Associação de espelhos cilíndricos convexos}

Essa é a atividade primária para a qual o modelo foi construído. Para que o mesmo representasse as edificações da PGR com maior fidelidade, adotou-se a Fig.9, a qual mostra um diagrama arquitetônico da fachada dos edifícios, como referência para a distância entre as lixeiras do modelo. Medições feitas com uma régua milimetrada sobre uma impressão da Fig.9 indicam que o diâmetro dos edifícios ( $2 R$, sendo $R$ o raio) é três vezes maior que a distância de separação entre eles $(d=2 R / 3)$.

Estabelecidas as proporções, percebe-se que para um diâmetro de $18 \mathrm{~cm}$ para os espelhos do modelo, a distância entre os mesmos deve ser igual a $6 \mathrm{~cm}$. Dispostos os espelhos nessa condição, obteve-se a fotografia representada na Fig. $10^{7}$.

Pode-se requerer que os estudantes comparem a imagem obtida com o modelo (Fig. 10) com a situação real (Fig. 2). Uma sugestão para essa comparação seria uma medição das dimensões vertical e horizontal dos prédios na fotografia da PGR, fazendo tais medidas de forma direta sobre o modelo, a fim de se verificar se há manutenção das proporções relativas. Convém ressaltar que tais medidas, quando feitas sobre uma foto impressa, poderão apresentar imprecisões, as quais são decorrentes do ato de fotografar um objeto utilizando uma lente convergente como objetiva, a qual sempre apresentará aberrações em algum grau.

As medições sugeridas acima foram durante a realização da atividade, e percebeu-se compatibilidade entre o modelo e os edifícios reais. Um exemplo dessa compatibilidade está na semelhança entre os valores da razão entre as dimensões horizontais da imagem refletida e do cilindro-objeto, tanto para os edifícios reais quanto para o modelo.

\footnotetext{
7 Para que o fotógrafo não aparecesse na foto, a câmera foi colocada em modo de disparo automático.
} 


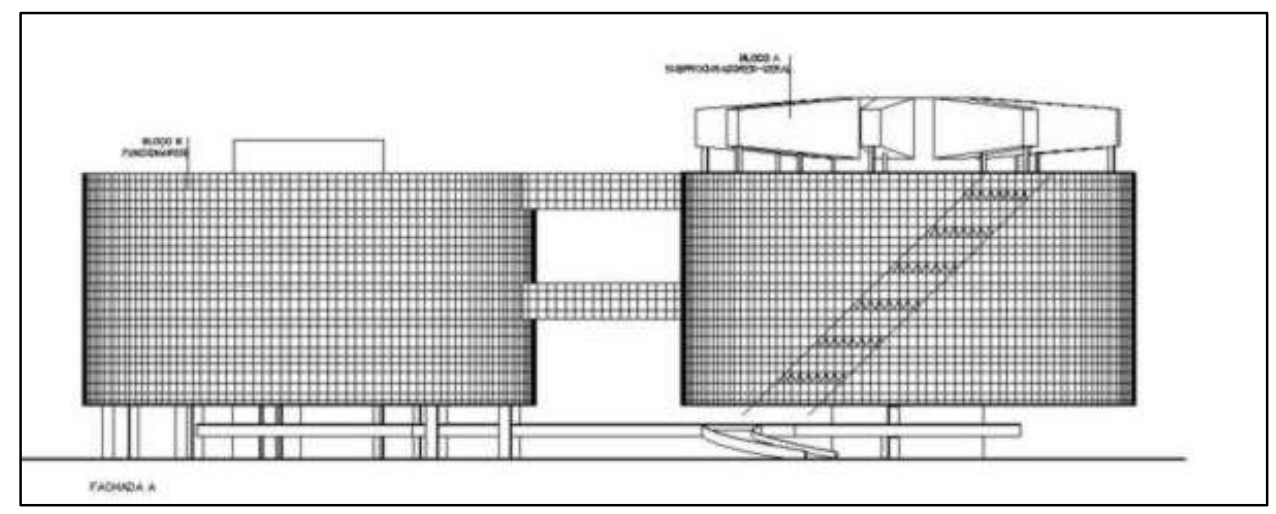

Fig. 9 - Projeto da fachada dos prédios principais da PGR Fonte: <http://www.pgr.mpf.mp.br/conheca-o-mpf/visitacao-a-pgr/copy_of_sobre-o-predio/pgr_desenho1.jpg >. (editado). Acesso em: 29 nov. 2014.

Uma discussão complementar que pode ser apresentada aos estudantes diz respeito à validade da equação dos pontos conjugados, a seguir ( $\mathrm{f}=$ distância focal; $\mathrm{p}=$ distância do objeto ao espelho; $\mathrm{p}^{\prime}=$ distância da imagem ao espelho):

$$
\frac{1}{f}=\frac{1}{p}+\frac{1}{p^{\prime}}
$$

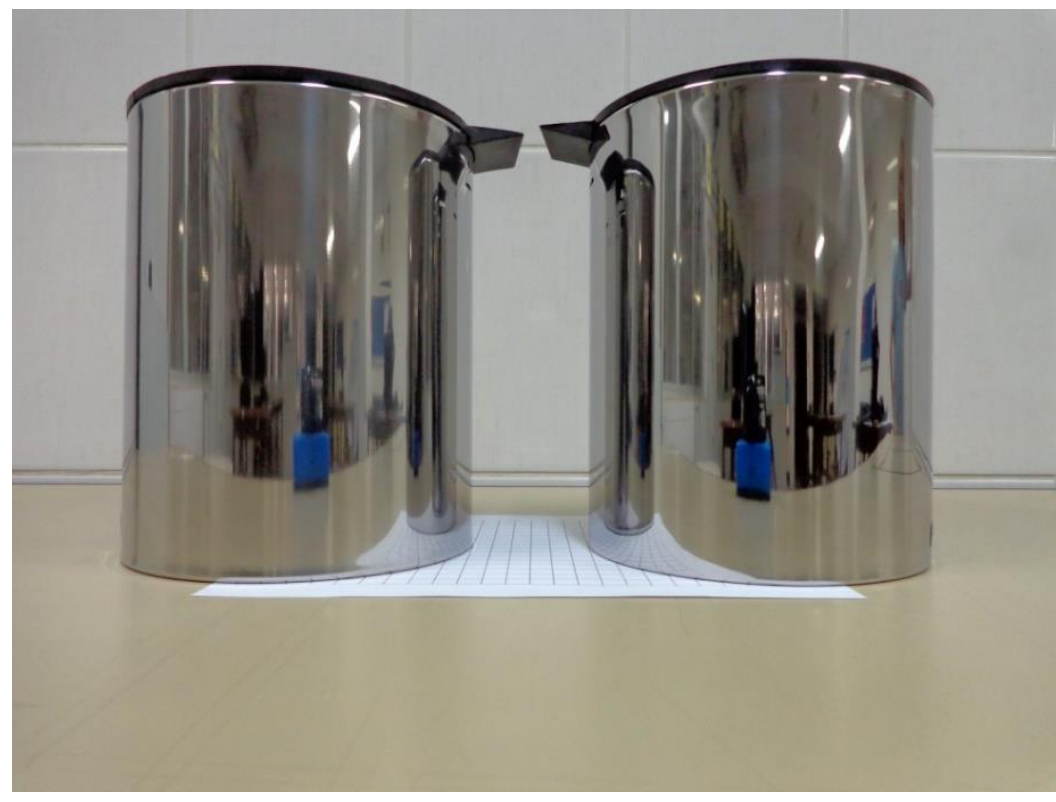

Fig. 10 - Atividade experimental 3.

Tal equação é demonstrada a partir da consideração de raios paraxiais e com pequenos ângulos de incidência, situação que não se aplica à configuração real aqui estudada. Na interpretação desta atividade experimental, se for considerado que apenas um semicírculo de raio $R$ é refletido e a distância mínima desse semicírculo até o vértice do espelho oposto é $2 R / 3$, a 
aplicação da eq. (1) levaria a uma imagem (Fig. 11) que deveria ter um comprimento horizontal igual a 9R/91 (aproximadamente $R / 10$ ). Entretanto, a medida direta no modelo e também sobre a fotografia da PGR (Fig. 2) permite concluir que essa medida é próxima de $R / 5$, demonstrando uma limitação da eq. (1).

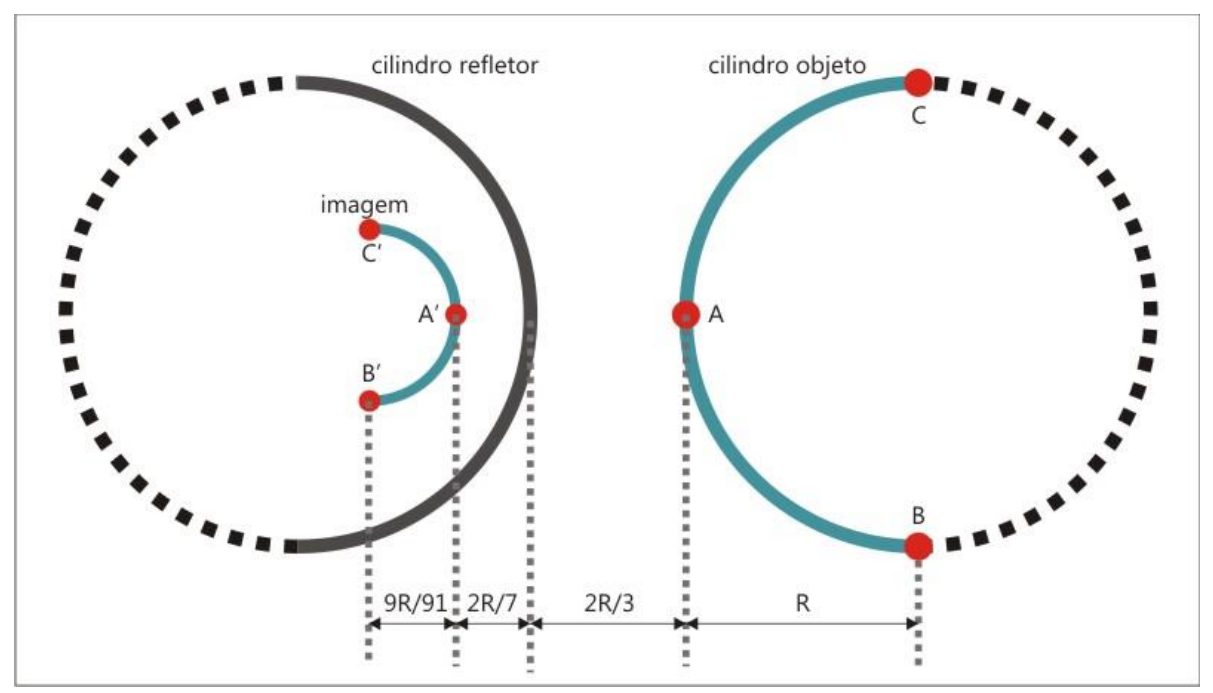

Fig. 11 - Dimensões teóricas da imagem de um semicírculo refletido na superfície convexa, sendo válidas as condições de aproximação de Gauss.

Essa medida, entretanto, traz alguma imprecisão, devido ao posicionamento central da câmera. Esta posição amplia o campo de visão do instrumento, permitindo que até mesmo partes do objeto que não deveriam estar visíveis (tal como a imagem do arco A'C') estejam presentes e ampliando a dimensão horizontal observada. Não consideramos, entretanto, que essa variação seja significativa o suficiente para que o resultado apresentado seja o dobro do teórico. A Fig. 11 traz outra imprecisão proposital: a imagem representada é estigmática, ou seja, mantém as proporções do objeto original, fato observado como falso na atividade experimental 2.

Outra possibilidade de discussão do experimento se relaciona com a altura vertical da imagem. Sendo o espelho plano em um corte vertical, a altura do objeto e da imagem deveria ser a mesma, fato que não é verificado na observação direta dos edifícios e do modelo. Acreditase que essa situação seja explicada pela distorção de perspectiva produzida pelo espelho convexo: a redução da imagem na horizontal é percebida pelo olho do observador como um afastamento do objeto (visão em perspectiva), levando a imagem como um todo a ser percebida como menor.

\section{V.4 Atividade experimental 4: Reflexões múltiplas}

Se espelhos planos são dispostos paralelos entre si, observa-se uma multiplicidade de reflexões, resultando em um grande número de imagens. A disposição dos cilindros refletores 
na atividade experimental 3 pode ser comparada com a associação de espelhos planos paralelos, pois também nesse experimento são observadas múltiplas imagens. Tais imagens progressivamente se tornam mais escuras, pois os espelhos não refletem toda a luz que os atinge, e também mais distorcidas em relação à forma original. Na Fig. 12, é possível identificar quatro imagens em cada espelho, sendo a mais interna visível apenas como uma mancha negra.

\section{Conclusões e perspectivas}

Buscou-se mostrar nesse artigo as possibilidades didáticas que uma análise de uma estrutura arquitetônica real pode trazer ao aprendizado da óptica, a partir de um modelo em escala reduzida. Como evidenciado pelas revisões bibliográficas, tanto o diálogo entre as disciplinas da arquitetura e da física é raro, tanto quanto a discussão sobre o modelo óptico trabalhado, uma associação de espelhos cilíndricos. Tais lacunas na literatura são, a nosso ver, uma primeira motivação para a apresentação desse artigo.

A discussão dos resultados experimentais obtidos com o modelo foi feita a partir de um tratamento geométrico e qualitativo, evitando-se o tratamento algébrico, pois a proposta deste trabalho é apresentar uma atividade experimental adequada ao ensino médio. A curva que interliga as imagens conjugadas por um ponto objeto disposto à frente de um espelho cilíndrico (chamada limaçon) foi desenvolvida por Deweerd e Hill (2005a), e sua extrapolação para a situação trabalhada no artigo presente, apresentando uma expressão algébrica para a forma da “curva-imagem" obtida (Fig. 8), foi reservada para um artigo posterior.

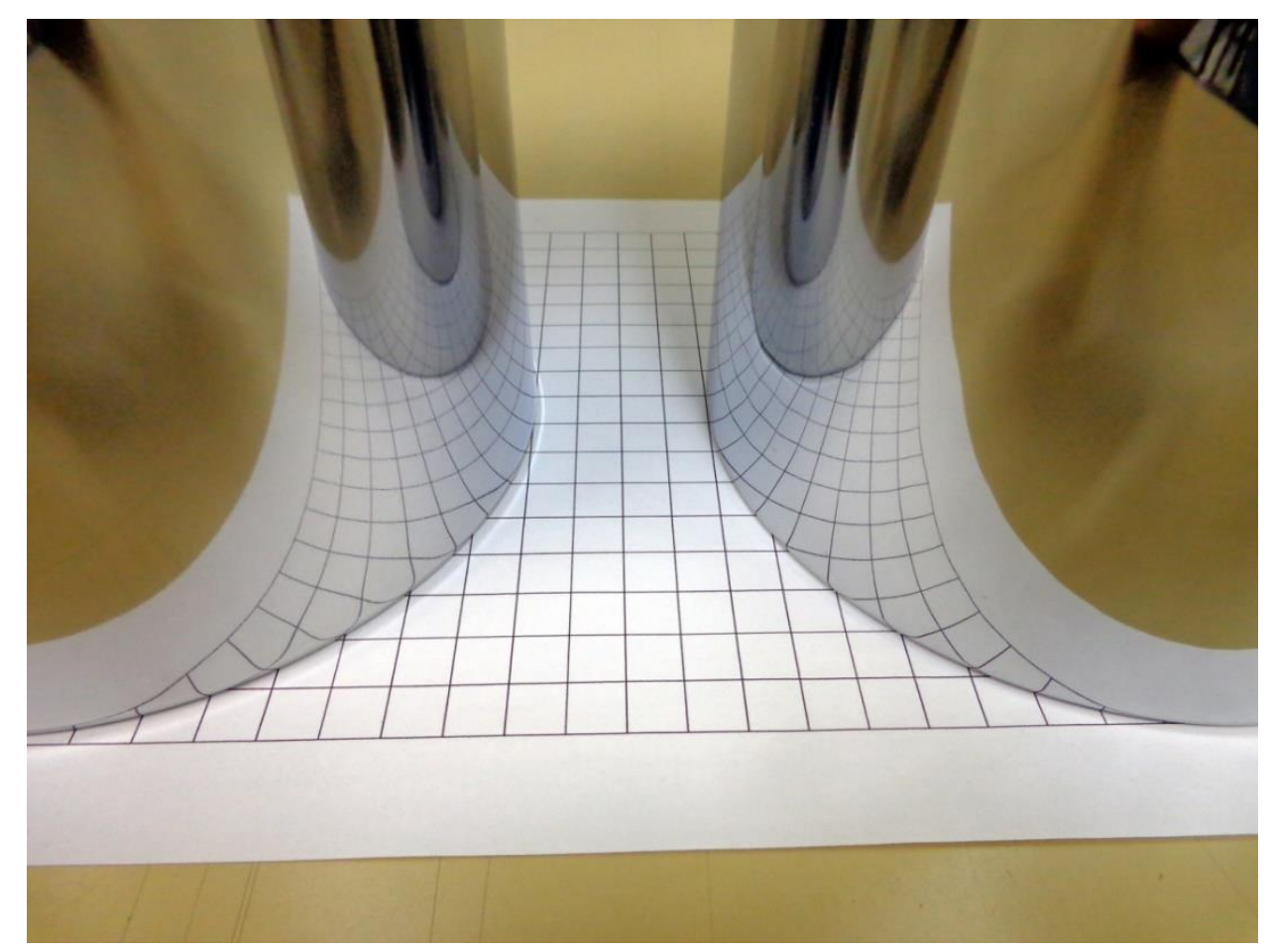

Fig. 12 - Imagens formadas por reflexões múltiplas. 
Como demonstrado pela revisão prévia à pesquisa, as diferentes aberrações ópticas não costumam ser trabalhadas em livros-texto, sejam eles voltados para o ensino médio ou superior, apesar de sua constante presença em sistemas ópticos reais (por vezes, tais aberrações são propositais, como a forte distorção de campo em uma lente fisheye). Assim como a idealização de sistemas mecânicos (ausência de atritos, resistência do ar, entre outras condições) pode trazer dificuldades para o aprendizado dos estudantes, o mesmo pode ser percebido em óptica. Assim, acredita-se que atividades experimentais dedicadas à exposição das limitações do modelo geométrico e algébrico apresentado podem se revelar valiosas para uma melhor compreensão da óptica geométrica por parte dos estudantes.

Prédios com fachadas espelhadas são cada vez mais frequentes em aglomerados urbanos, e as propriedades ópticas de tais superfícies são negligenciadas pelos próprios projetistas. Uma grande superfície refletora inevitavelmente conjugará imagens dos seus arredores, podendo causar alterações nas condições de iluminação e aquecimento da periferia do prédio, ou até mesmo à estética da região. Evidenciar tais alterações aos estudantes, interligando a óptica com os temas do planejamento urbanístico e arquitetônico, pode ajudar a despertar o interesse dos estudantes por assuntos por vezes considerados estéreis, tais como os espelhos curvos e suas imagens.

\section{Referências}

ACIOLI, J. Física básica para arquitetura. 1. ed. Brasília: Editora UnB, 1994.

ANASTASSAKIS, E. Physics for architects. European Journal of Physics, v. 3, n. 4, p. 247249, 1982.

ANJOS, I. Física para o ensino médio. 1. ed. São Paulo: IBEP, 2005. p. 271-280. v. único.

BONJORNO, J.; BONJORNO, R.; BONJORNO, V.; RAMOS, C.; ALVES, L. Física: termologia, óptica e ondulatória. 1. ed. São Paulo: FTD, 2010. p. 222-226. v. 2.

CATELLI, F.; VICENZI, S. Óptica geométrica no café da manhã. Caderno Brasileiro de Ensino de Física, v. 21, n. 3, p. 392-400, 2004.

DEWEERD, A.; HILL, S. Optics over a cup of tea: images in concave and convex surfaces, Physics Education, v.40, n.1, p.13-14, 2005.

DEWEERD, A.; HILL, S. The dizzying depths of the cylindrical mirror. The Physics Teacher, v. 43, n. 2, p. 90-92, 2005 a.

DEWEERD, A.; HILL, S. Comment on “Anamorphic images," by J. Hunt, B. Nickel and C. Gigault. American Journal of Physics, v. 73, n. 6, 2005b. 
DRUDE, P. The theory of optics. 1. ed. London; New York: Longmans, Green, and Co., 1959. p. 33-67.

DURAND, J.; SALVATORI, E. Por uma nova agenda de pesquisa em torno de Oscar Niemeyer. Arquitextos, v. 11, n. 130.06, 2011.

GUERRA, H. Edifício comercial em Londres reflete luz solar quente, o suficiente para fritar um ovo. Vitruvius, v. 14, n. 072.01, 2013.

GUIMARÃES, L.; FONTE BOA, M. Física: Termologia, Óptica e Ondas. 1. ed. Niterói: Galera Hipermídia, 2005. p. 211-227.

GUIMARÃES, O.; PIQUEIRA, J.; CARRON, W. Física 2. 1. ed. São Paulo: Ática, 2013. p. 229-240.

HALLIDAY, D.; RESNICK, R.; WALKER, J. Fundamentals of Physics. 9 ed. (extended), New York: John Wiley \& Sons, 2011. p. 925-957.

HETCH, E. Optics. 4. ed. Pearson/Addison-Wesley, 2002. p. 258-281.

HOLZBERlEIN, T. How to become dizzy with Derman's optical puzzle. The Physics Teacher, v. 20, n. 6, p. 401-402, 1982.

HUNT, J.; NICKEL, B.; GIGAULT, C. Anamorphic images. American Journal of Physics, v. 68 , n. 3, p. 232-237, 2000.

JOHNSON, B. Optics and optical instruments: an introduction with special reference to practical applications. 1. ed. New York, Dover, 1960. p.110-134.

KAMITA, J. A graça estética da arquitetura de Oscar Niemeyer. Arquitextos, v. 13, n. 151.07, 2012.

KNIGHT, R. Física 2: uma abordagem estratégica. 2. ed. Porto Alegre: Bookman, 2009. p. 728-731.

LARA, F. A insustentável leveza da modernidade. Arquitextos, v. 5, n. 05.057, 2005.

MÁXimO, A.; AlvarengA, B. Curso de Física. 1. ed. São Paulo: Scipione, 2005. v. 2. p.172-193.

NIEMEYER, O. A forma na arquitetura. 1. ed. Rio de Janeiro: Avenir, 1978.

NUSSENZVEIG, H. Curso de física básica. 1. ed. São Paulo: Blucher, 1998. p.18-24. v. 4.

O'SHEA, D.; HARRIGAN, M. Aberration curves in lens design. Handbook of Optics (ed. M. Bass). 2. ed. New York: McGraw Hill, 1995. p. 33.1-33.7. 
PIETROCOLA, M.; POGIBIN, A.; OLIVEIRA, R.; ROMERO, T. Física em contextos: pessoal, social e histórico - energia, calor, imagem e som. 1. ed. São Paulo: FTD, 2011. p. 355404. v. 2.

PIZZATO, E. Curvas na obra de Oscar Niemeyer. Arquitextos, v. 10/11, n. 1, 2007.

RAMALHO, F.; FERRARO, N.; TOLEDO, P. Os fundamentos da física: Termologia, óptica e ondas. 9. ed. São Paulo: Moderna, 2007. p. 260-283. v. 2.

RÖMER, H. Theoretical optics: an introduction. 1. ed. Weinheim: Wiley-VCH, 2005. p.143166.

ROSSETTI, E. Arquiteturas de Brasília. 1. ed. Brasília: Instituto Terceiro Setor, 2012. p. 107108.

SALAMO, G.; BREWER, J.; BERRY, J. Physics for architects. American Journal of Physics, v. 47, n. 1, p. 24-28, 1979.

SALU, Y. Physics for Architects. 2. ed. Conshohocken: Infinity Publishing, 2004.

SAMPAIO, C. Espelho cilíndrico e imagem anamórfica, CiênciaMão, 2013. Disponível em: <http://www.cienciamao.usp.br/tudo/exibir.php?midia=amm\&cod=_espelhocilindricoeimagemanamorfica>. Acesso em: 02 dez. 2014.

SEGRE, R. Oscar Niemeyer, 100 anos, 100 obras. 1. ed. São Paulo: Instituto Tomie Ohtake, 2007. p. 174-277.

SERWEY, R.; JEWETT, J. Physics for scientists and engineers. 6. ed. Belmont: Brooks Cole, 2003. p.1124-1154.

SILVA, C.; BARRETO, B. Física aula por aula. 1. ed. São Paulo: FTD, 2008. p. 285-296. v. 2 .

SILVA, E. Matéria, ideia e forma: uma definição de arquitetura. 1. ed. Porto Alegre: Ed. Universidade/UFRGS, 1994. p. 91-100.

STROETER, J. Arquitetura e teorias. 1. ed. São Paulo: Nobel, 1986. p. 35-58.

TIPLER, P.; MOSCA, G. Physics for scientists and engineers: with modern physics. 1. ed. New York: W. H. Freeman and Company, 2008. p. 1097-1140.

VILLAS-BÔAS, H.; DOCA, R.; BISCUOLA, G. Conecte Física 2. 1. ed. São Paulo: Saraiva, 2011. p. 314-334.

VOLLMER, M.; MÖLLMANN, K. European Journal of Physics, v. 33, n. 5, p. 1429-1455, 2012.

YOUNG, H.; FREEDMAN, R. Física IV: ótica e física moderna. 2. ed. São Paulo: Addison Wesley, 2009. p. 40-47. 